Marquette University

e-Publications@Marquette

Physics Faculty Research and Publications

Physics, Department of

4-1-2000

\title{
Divalent Metal Binding Properties of the Methionyl Aminopeptidase from Escherichia coli
}

Ventris M. D'Souza

Utah State University

Brian Bennett

Marquette University, brian.bennett@marquette.edu

Alicja J. Copik

Utah State University

Richard C. Holz

Marquette University, richard.holz@marquette.edu

Accepted version. Biochemistry, Vol. 39, No. 13 (April 2000): 3817-3826. DOI. (C) 2000 American Chemical Society. Used with permission.

Brian Bennett and Richard Holz were affiliated with Utah State University at the time of publication. 


\section{Marquette University}

\section{e-Publications@Marquette}

\section{Physics Faculty Research and Publications/College of Arts and Sciences}

This paper is NOT THE PUBLISHED VERSION; but the author's final, peer-reviewed manuscript. The published version may be accessed by following the link in the citation below.

Biochemistry. Vol. 39, No. 13 (2000): 3817-3826. DOI. This article is (C American Chemical Society and permission has been granted for this version to appear in e-Publications@Marquette. American Chemical Society does not grant permission for this article to be further copied/distributed or hosted elsewhere without the express permission from American Chemical Society.

\section{Divalent Metal Binding Properties of the Methionyl Aminopeptidase from Escherichia coli}

Ventris M. D'souza

Department of Chemistry and Biochemistry, Utah State University, Logan, Utah

Brian Bennett

Department of Chemistry and Biochemistry, Utah State University, Logan, Utah Department of Physics, Marquette University, Milwaukee, WI

\section{Alicja J. Copik}

Department of Chemistry and Biochemistry, Utah State University, Logan, Utah

Richard C. Holz

Department of Chemistry and Biochemistry, Utah State University, Logan, Utah Department of Chemistry, Marquette University, Milwaukee, WI

\section{Abstract}

The metal-binding properties of the methionyl aminopeptidase from Escherichia coli (MetAP) were investigated. Measurements of catalytic activity as a function of added $\mathrm{Co}$ (II) and Fe(II) revealed that maximal enzymatic 
activity is observed after the addition of only 1 equiv of divalent metal ion. Based on these studies, metal binding constants for the first metal binding event were found to be $0.3 \pm 0.2 \mu \mathrm{M}$ and $0.2 \pm 0.2 \mu \mathrm{M}$ for $\mathrm{Co}$ (II)and Fe(II)-substituted MetAP, respectively. Binding of excess metal ions ( $>50$ equiv) resulted in the loss of $\sim 50 \%$ of the catalytic activity. Electronic absorption spectral titration of a $1 \mathrm{mM}$ sample of MetAP with Co(II) provided a binding constant of $2.5 \pm 0.5 \mathrm{mM}$ for the second metal binding site. Furthermore, the electronic absorption spectra of $\mathrm{Co}$ (II)-loaded MetAP indicated that both metal ions reside in a pentacoordinate geometry. Consistent with the absorption data, electron paramagnetic resonance (EPR) spectra of [CoCo(MetAP)] also indicated that the $\mathrm{Co}$ (II) geometries are not highly constrained, suggesting that each Co(II) ion in MetAP resides in a pentacoordinate geometry. EPR studies on [CoCo(MetAP)] also revealed that at $\mathrm{pH} 7.5$ there is no significant spin-coupling between the two Co(II) ions, though a small proportion ( $\sim 5 \%)$ of the sample exhibited detectable spin-spin interactions at pH values > 9.6. EPR studies on [Fe(III)_(MetAP)] and [Fe(III)Fe(III)(MetAP)] also suggested no spin-coupling between the two metal ions. ${ }^{1} \mathrm{H}$ nuclear magnetic resonance (NMR) spectra of [Co(II)_(MetAP)] in both $\mathrm{H}_{2} \mathrm{O}$ and $\mathrm{D}_{2} \mathrm{O}$ buffer indicated that the first metal binding site contains the only activesite histidine residue, His171. Mechanistic implications of the observed binding properties of divalent metal ions to the MetAP from E. coli are discussed.

\section{Introduction}

Methionyl aminopeptidases (MetAPs) ${ }^{1}$ are ubiquitous enzymes found in both eukaryotic and prokaryotic cells. They are involved in the selective removal of the initiator $\mathrm{N}$-terminal methionine residue from newly synthesized polypeptide chains (1-4). In the cytosol of eukaryotes, all proteins are initiated with an $\mathrm{N}$-terminal methionine residue; however, all proteins synthesized in prokaryotes, mitochondria, and chloroplasts are initiated with an $\mathrm{N}$-terminal formylmethionyl residue that is subsequently removed by a deformylase (2). Removal of $\mathrm{N}$-terminal methionine residues is essential for cotranslational and posttranslational modifications that are critical for fully functional enzymes, correct cellular localization, and the timely degradation of proteins $(\underline{1-4})$. Deletion of the gene encoding MetAP is lethal to Escherichia coli, Salmonella typhimurium, and Saccharomyces cerevisiae; therefore, MetAPs are essential for cell growth and proliferation ( $\underline{5-7})$. An important physiologic role for MetAPs involves angiogenesis, the formation of new blood vessels, which is essential for tumor growth. Recently, MetAPs have been identified as the molecular target for the epoxide-containing, anti-angiogenesis agents ovalicin and fumagillin, one of which is in phase III clinical trials ( $\underline{8-12})$. Thus, the inhibition of aminopeptidase activity in malignant tumors is critically important in preventing the growth and proliferation of these types of cells.

The MetAPs from E. coli, Homo sapiens, and Pyrococcus furiosus have been crystallographically characterized $(\underline{12-15})$. These MetAPs and all other MetAPs studied to date have been shown to have identical catalytic domains that contain a bis( $\mu$-carboxylato)( $\mu$-aquo/hydroxo)dicobalt core with an additional carboxylate residue at each metal site and a single histidine residue bound to one of the two metal ions $(\underline{12-15})$. A recent $1.9 \AA$ resolution crystal structure of the MetAP from E. coli (14) indicated the presence of two solvent molecules in the active site, one of which bridges the two $\mathrm{Co}(\mathrm{II})$ ions while the second acts as a terminal ligand coordinated to the non-histidine-ligated Co(II) ion. In all three structures, the histidine-ligated Co(II) ion appears to reside in a trigonal bipyramidal coordination environment while the second Co(II) ion is either trigonal bipyramidal or octahedral.

Until recently, all MetAPs studied had been reported to be Co(II)-dependent metalloproteases $(\underline{16,17)}$. Walker and Bradshaw (18) suggested that the type-I MetAP from S. cerevisiae is a Zn(II)-dependent enzyme; however, the type I MetAP from E. coli was more recently shown to have only trace amounts of activity with $\mathrm{Zn}(\mathrm{II})$ but is fully active with $\mathrm{Co}(\mathrm{II})$ or Fe(II) and partially active with $\mathrm{Mn}$ (II) (19). Several metalloproteases with similar activesite ligands to those of MetAPs can be substituted with various divalent metal ions in vitro and, in many cases, active and even hyperactive enzymes are obtained $(\underline{20}, 21)$. The previous conclusion that MetAPs are Co(II)dependent enzymes was arrived at from the reproducible observations that MetAPs show high activity in the presence of $\mathrm{Co}$ (II) when compared to the activity levels of other divalent metal ions. However, in all in vitro 
studies to date, $\mathrm{Co}(\mathrm{II})$ concentrations have been artificially increased to the millimolar range during purification, but unlike Co(II), the remaining divalent metal ions that provide MetAP activity [Fe(II), Mn(II), and Zn(II)] are abundant in nature and have many reported biological roles (19). Even so, the identity of the in vivo metal ions for MetAPs has not been established (19).

In an effort to establish the catalytic roles of each divalent metal ion in MetAPs, we have explored the divalent metal binding properties of the MetAP from E. coli. On the basis of kinetic, electronic absorption, NMR, and EPR spectroscopies, the metal binding constants and the structural/electronic properties of the Co(II)- and Fe(II)loaded MetAP enzymes have been determined. These data are discussed in relation to the chemical properties of these metal ions and the known ligand environment of the MetAP active site. The implications of the observed binding properties of these divalent metal ions, with respect to their likely physiological roles in the MetAP from $E$. coli, are also discussed.

\section{Materials and Methods}

Protein Expression and Purification. The recombinant MetAP from E. coli was expressed and purified as previously described from a stock culture kindly provided by Drs. Brian W. Matthews and W. Todd Lowther (11, 19). The purified MetAP from E. coli exhibited a single band on SDS-PAGE and a single symmetrical peak in matrix-assisted laser desorption ionization time-of-flight (MALDI-TOF) spectrometric analysis indicating $M_{\mathrm{r}}=$ $29630 \pm 10$. Protein concentrations were estimated from the absorbance at $280 \mathrm{~nm}$ with an extinction coefficient of $16445 \mathrm{M}^{-1} \mathrm{~cm}^{-1}(\underline{11}, 19)$. Apo-MetAP samples were exchanged into $25 \mathrm{mM}$ Hepes, $\mathrm{pH} 7.5$, containing $150 \mathrm{mM} \mathrm{KCl}$ (Centricon-10, Millipore Corp). Individual aliquots were stored in liquid nitrogen until needed.

Metal Content Measurements. Enzyme samples for metal analyses were typically $30 \mu \mathrm{M}$. Apo-MetAP samples were incubated anaerobically with $\mathrm{MCl}_{2}$, where $\mathrm{M}=\mathrm{Co}(\mathrm{II})$, $\mathrm{Fe}(\mathrm{II})$, or $\mathrm{Zn}(\mathrm{II})$, for 30 min prior to exhaustive anaerobic exchange into Chelex-treated buffer as previously reported (19). Analyses were performed by inductively coupled plasma-atomic emission spectrometry (ICP-AES).

Enzymatic Assay of MetAP. MetAP was assayed for catalytic activity with Met-Gly-Met-Met as substrate (8 mM) by an HPLC method as previously described (19). This method is based on the spectrophotometric quantitation of the reaction product Gly-Met-Met at $215 \mathrm{~nm}$ following separation on a C8 HPLC column (Phenomenex, Luna; $5 \mu \mathrm{m}, 4.6 \times 25 \mathrm{~cm}$ ). The kinetic parameters $v$ (velocity) and $K_{\mathrm{m}}$ (Michaelis constant) were determined at $\mathrm{pH} 7.5$ by quantifying the tripeptide Gly-Met-Met at $215 \mathrm{~nm}$ in triplicate. Enzyme activities are expressed as units per milligram, where one unit is defined as the amount of enzyme that releases $1 \mu \mathrm{mol}$ of Gly-Met-Met at $30{ }^{\circ} \mathrm{C}$ in 1 min. Catalytic activities were determined with an error of $\pm 10 \%$.

Spectroscopic Measurements. Electronic absorption spectra were recorded on a Shimadzu UV-3101PC spectrophotometer. All apo-MetAP samples used in spectroscopic measurements were made rigorously anaerobic prior to incubation with $\mathrm{Co}$ (II) or $\mathrm{Fe}(\mathrm{II})\left(\mathrm{CoCl}_{2} \geq 99.999 \% \mathrm{Fe}\left(\mathrm{NH}_{4}\right)_{2}\left(\mathrm{SO}_{4}\right)_{2}>99 \%\right.$ Strem Chemicals, Newburyport, MA) for $\sim 30 \mathrm{~min}$ at $20-25^{\circ} \mathrm{C}$. All Co(II)- and Fe(II)-containing samples were handled throughout in an anaerobic glovebox $\left(\mathrm{Ar} / 5 \% \mathrm{H}_{2}, \leq 1 \mathrm{ppm} \mathrm{\textrm {O } _ { 2 }}\right.$; Coy Laboratories) until frozen. Fe(III)-containing MetAP was generated by exposure of Fe(II)-containing MetAP to air for $20 \mathrm{~min}$ at $25^{\circ} \mathrm{C}$. Electronic absorption spectra were normalized for the protein concentration and the absorption due to uncomplexed $\operatorname{Co}(I I)\left(\varepsilon_{512 \mathrm{~nm}}=6.0 \mathrm{M}^{-1} \mathrm{~cm}^{-1}\right)$. Low-temperature EPR spectroscopy was performed on a Bruker ESP-300E spectrometer equipped with an ER 4116 DM dual-mode X-band cavity and an Oxford Instruments ESR-900 helium flow cryostat. Background spectra recorded on a buffer sample were aligned with and subtracted from experimental spectra as in earlier work $(22,23)$. EPR spectra were recorded at microwave frequencies of approximately $9.65 \mathrm{GHz}$ : precise microwave frequencies were recorded for individual spectra to ensure precise $g$ alignment. All spectra were 
recorded at $100 \mathrm{kHz}$ modulation frequency. Other EPR running parameters are specified in the figure captions for individual samples. The protocol for computer simulation of high-spin Co(II) EPR spectra is described elsewhere in detail $(\underline{22,23})$. Enzyme concentrations for EPR were typically 2-4 mM. Samples for EPR were frozen after incubation of MetAP with the appropriate amount of metal ion for $60 \mathrm{~min}$ at $25^{\circ} \mathrm{C}$.

Proton NMR spectra were recorded on a Bruker ARX-400 spectrometer at $400.13 \mathrm{MHz}$. A presaturation pulse sequence was used to suppress the water signal and the resonances in the diamagnetic region. The pulse sequence repetition rate was typically $5 \mathrm{~s}^{-1}$ with a spectral window of $83 \mathrm{kHz}$. Chemical shifts (in parts per million) were referenced to the residual water peak at $4.7 \mathrm{ppm}$. The ${ }^{1} \mathrm{H}$ NMR data were Fourier-transformed with an exponential apodization function as well as the application of a $30 \mathrm{~Hz}$ line broadening function. Nonbaseline-subtracted spectra were used to determine peak areas by the cut-and-weigh method. Enzyme concentrations for NMR samples were typically $2 \mathrm{mM}$ and the sample were placed in sealed, anaerobic NMR tubes (Wilmad, Buena, NJ).

\section{Results}

Analyses of the Metal lon Content of MetAP. The number of tightly bound divalent metal ions was determined for the MetAP from E. coli by ICP-AES analysis. MetAP samples $(30 \mu \mathrm{M})$ to which 2-30 equiv of either Co(II) or $\mathrm{Fe}(\mathrm{II})$ were added were washed extensively for $3 \mathrm{~h}$ at $4{ }^{\circ} \mathrm{C}$ with metal-free Hepes buffer. Upon ICP-AES analysis, $1.0 \pm 0.1$ equiv of cobalt or iron was found to be associated with MetAP. These data suggest that only one Co(II) or Fe(II) ion is tightly bound to MetAP while the second metal ion is labile on the time scale of the buffer exchange $\left(3 \mathrm{~h}, 4^{\circ} \mathrm{C}\right)$. On the other hand, the addition of 3-30 equiv of $\mathrm{Zn}(\mathrm{II})$ to apo-MetAP $(30 \mu \mathrm{M})$ followed by extensive washing with metal-free Hepes buffer at $4{ }^{\circ} \mathrm{C}$ provided an enzyme with $3.0 \pm 0.1$ equiv of tightly bound zinc. However, the addition of reduced glutathione to anaerobic samples of MetAP containing 3 to 30 equiv of $\mathrm{Zn}(\mathrm{II})$, followed by extensive washing at $4{ }^{\circ} \mathrm{C}$ with metal-free Hepes buffer, provided an enzyme with $1.3 \pm 0.1$ equiv of tightly associated zinc.

In a separate experiment, 2 equiv of $\mathrm{Co}(\mathrm{II})$ or Fe(II) were added to apo-MetAP ( $30 \mu \mathrm{M})$ after which they were oxidized in air to form the trivalent state. The addition of hydrogen peroxide to the Co(II)-loaded MetAP enzyme resulted in a distinct color change from violet/pink to brown, indicative of the formation of low-spin octahedral $\mathrm{Co}(\mathrm{III})$. Moreover, no EPR spectrum could be detected, consistent with diamagnetic Co(III) ions. After extensive washing at $4{ }^{\circ} \mathrm{C}$ with metal-free Hepes buffer, 2 equiv of cobalt or iron were found associated with MetAP by ICP-AES analysis. These data suggest that $\mathrm{Co}(\mathrm{II})$ and $\mathrm{Fe}(\mathrm{II})$ are oxidized to $\mathrm{Co}(\mathrm{III})$ and $\mathrm{Fe}(\mathrm{III})$, forming [Co(III)Co(III)MetAP] and [Fe(III)Fe(III)(MetAP)] enzymes.

MetAP Activity as a Function of Divalent Metal Ion Concentration. The extent of hydrolytic activity exhibited by the MetAP from E. coli was determined as a function of divalent metal ion concentration. Apo-MAP (20 $\mu$ M) was incubated with varying amounts of $\mathrm{Co}(\mathrm{II}), \mathrm{Fe}(\mathrm{II})$, or $\mathrm{Zn}(\mathrm{II})$ and the level of catalytic activity was determined (Figure 1). Upon the addition of Co(II) to the MetAP from E. coli, the specific activity increased as a function of metal ion concentration and exhibited a maximum activity of $\sim 35$ units $\mathrm{mg}^{-1}$ after the addition of only 1 equiv of Co(II). Further additions of up to 4 equiv of $\mathrm{Co}$ (II) had no effect on the enzymatic activity. Interestingly, upon the addition of $\mathrm{Co}$ (II) to $>1 \mathrm{mM}$ ( $>50$ equiv) the activity steadily decreased until $\sim 2 \mathrm{mM} \mathrm{Co}$ (II) had been added, at which time the activity was $\sim 17$ units $\mathrm{mg}^{-1}$ (Figure 1 ). Further addition resulted in little change in the observed level of activity. This decrease in activity could be due to the occupation of a second metal binding site or may be the result of chelation of the tetrapeptide substrate by excess divalent metal ions. Analogous behavior was

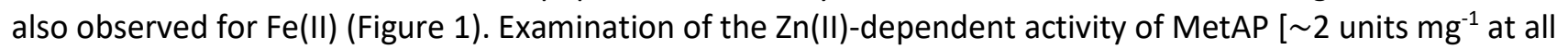
$\mathrm{Zn}$ (II) ion concentrations] was at or below the detection limit of our assay (Figure 1). Therefore, Zn(II) does not appear to stimulate MetAP activity under our current reaction conditions. 


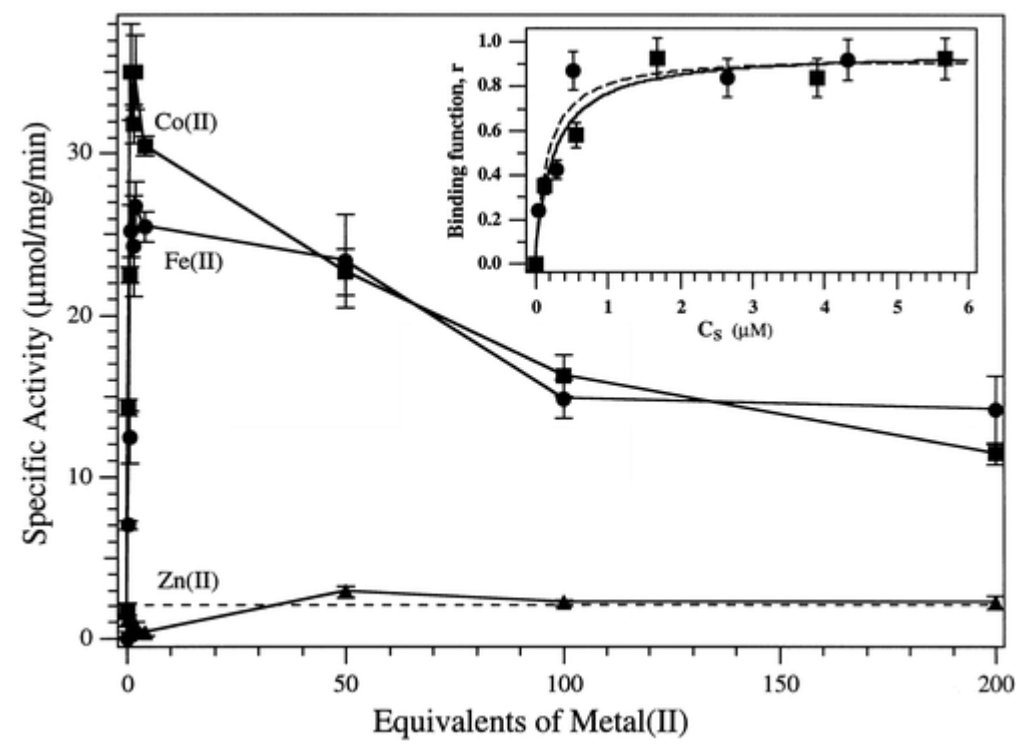

Figure 1 Plot of specific activity of the MetAP from E. coli vs equivalents of added metal ion. The symbols represent the various metal ions: ( $\Delta$ ) zinc(II), (·) iron(II), (·) cobalt(II). Inset: Fits of the Co(II) (solid line) and $\mathrm{Fe}(\mathrm{II})$ (dashed line) activity data to eq 1.

The activity titration data for Co(II) and Fe(II) binding to MetAP were fit to (24)

$$
r=p C_{s} / K_{d}+C_{S}
$$

where $p$ is the number of sites for which interaction with $\mathrm{M}(\mathrm{II})$ is governed by the intrinsic dissociation constant $K_{\mathrm{d}}$ and $r$ is the binding function calculated by conversion of the fractional saturation $\left(f_{\mathrm{a}}\right)$ :

$$
r=f_{a} p
$$

$C_{s}$, the free metal concentration, was calculated from

$$
C_{S}=C_{T S}-r C_{A}
$$

where $C_{\mathrm{TS}}$ and $C_{\mathrm{A}}$ are the total molar concentrations of metal and enzyme, respectively. A value for the dissociation constant $\left(K_{\mathrm{d}}\right)$ was obtained by fitting the data via an iterative process that allowed both $K_{\mathrm{d}}$ and $p$ to vary (Figure 1, inset). The best fit obtained provided a $p$ value of 1 and $K_{\mathrm{d}}$ values of $0.3+0.2$ and $0.2 \pm 0.2 \mu \mathrm{M}$ for Co(II)-, and Fe(II)-substituted MetAP, respectively.

Electronic Absorption Spectra of Co(II)-Bound MetAP. The electronic absorption spectrum of the MetAP from E. coli with various amounts of Co(II) added was recorded under strict anaerobic conditions in $25 \mathrm{mM}$ Hepes buffer, $\mathrm{pH} 7.5$, and $150 \mathrm{mM} \mathrm{KCl}$ (Figure 2). The addition of one Co(II) ion to MetAP provided an electronic absorption spectrum with $\lambda_{\max }$ values of $580\left(\varepsilon_{580}=55 \mathrm{M}^{-1} \mathrm{~cm}^{-1}\right), 630\left(\varepsilon_{630}=40 \mathrm{M}^{-1} \mathrm{~cm}^{-1}\right)$, and $690 \mathrm{~nm}\left(\varepsilon_{680}=20\right.$ $\left.\mathrm{M}^{-1} \mathrm{~cm}^{-1}\right)$. Further addition of $\mathrm{Co}(\mathrm{II})$ resulted in increases in absorption at 580 and $630 \mathrm{~nm}$, consistent with occupation of additional metal-binding sites (Figure 2). In addition, an absorption band was also observed at 525 $\mathrm{nm}$ only after the addition of 2 equiv of $\mathrm{Co}(\mathrm{II})$, suggesting a third, weakly coordinated $\mathrm{Co}(\mathrm{II})$ ion. The dissociation constants $\left(K_{\mathrm{d}}\right)$ for the second and/ or third divalent metal binding sites were obtained by fitting these data to eq 1 or eq 4 for two separate binding sites:

$$
r=\left[p C_{S} /\left(K_{d 1}+C_{S}\right)\right]+\left[q C_{S} / K_{d 2} C_{S}\right]
$$


via an iterative process that allowed both $K_{\mathrm{d}}$ and $p / q$ to vary (Figure 3 ). The best fit obtained (Table 1 ) provided a $p$ value of 1 and $K_{\mathrm{d}}$ values of $3.0 \pm 0.5,2.4 \pm 0.5$, and $2.7 \pm 0.5 \mathrm{mM}$, respectively.

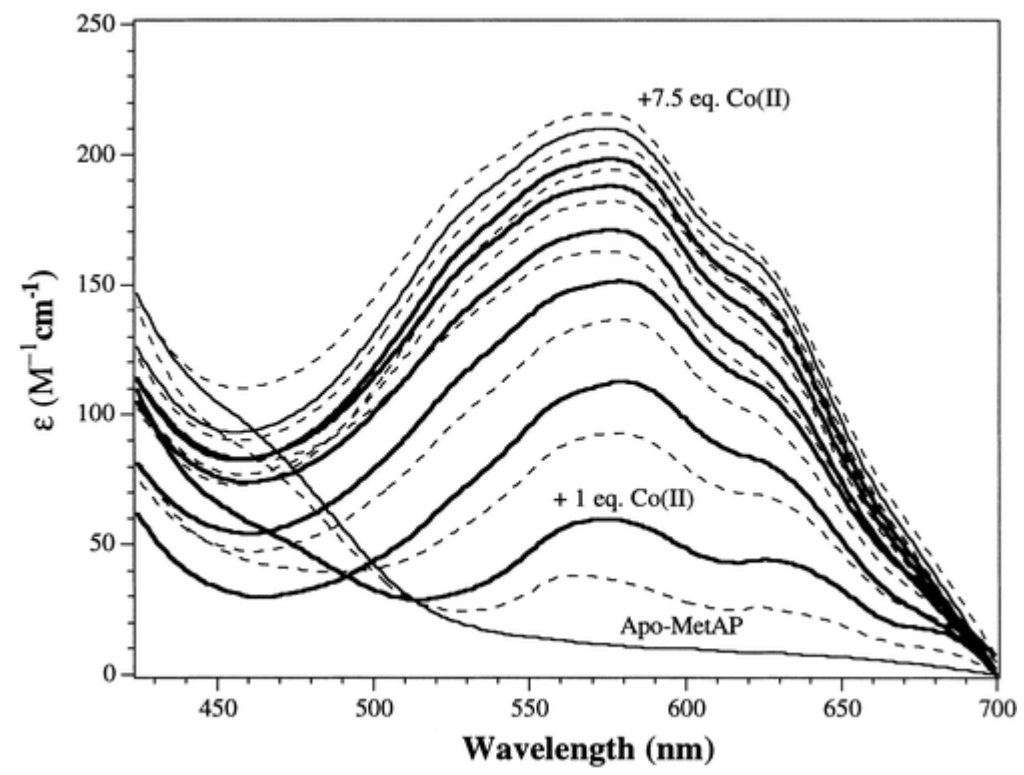

Figure 2 Electronic absorption spectral titration of a $1 \mathrm{mM}$ MetAP sample (25 mM Hepes buffer, pH 7.5, $150 \mathrm{mM}$ $\mathrm{KCl})$ with $\mathrm{Co}(\mathrm{II})$ in 0.5 equiv increments.

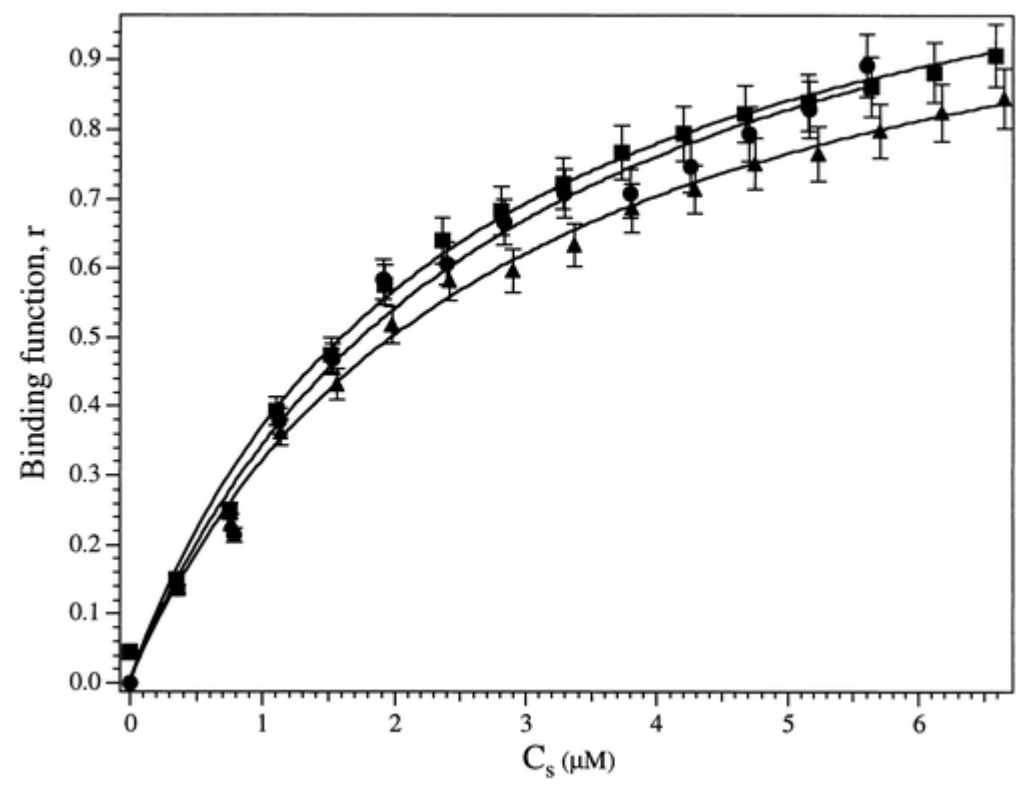

Figure 3 Binding function, $r$, vs $C_{s}$, the concentration of free metal ions in solution, for $\lambda_{525}(\cdot), \lambda_{580}(\cdot)$, and $\lambda_{630}(\Delta)$ of a $1 \mathrm{mM}$ MetAP sample ( $25 \mathrm{mM}$ Hepes buffer, $\mathrm{pH} 7.5$, and $150 \mathrm{mM} \mathrm{KCl}$ ). The solid lines correspond to the fits of each data set to eq 1.

Table 1: Data Obtained for the Fits of Electronic Absorption Data to Equations 1 (One Site) and 4 (Two Sites)

\begin{tabular}{|c|c|c|c|c|c|}
\hline one site & & & two sites & & \\
\hline & & & & & \\
\hline$\lambda_{\max }(\mathrm{nm})$ & $K_{\mathrm{d}(\mathrm{mM})}$ & $\chi^{2 a}$ & $K_{\mathrm{d} 1}(\mathrm{mM})$ & $K_{\mathrm{d} 2}(\mathrm{mM})$ & $\chi^{2 a}$ \\
\hline
\end{tabular}




\begin{tabular}{|l|l|l|l|l|l|}
\hline 525 & $3.0 \pm 0.5$ & 0.013 & 1.2 & 1.2 & 0.11 \\
\hline 580 & $2.4 \pm 0.5$ & 0.006 & 1.0 & 1.0 & 0.081 \\
\hline 625 & $2.7 \pm 0.5$ & 0.005 & 1.4 & 1.4 & 0.076 \\
\hline
\end{tabular}

${ }^{a}$ Goodness of fit.

EPR Studies of Cobalt- and Iron-Loaded MetAP. An EPR spectrum of MetAP (3.85 mM MetAP in 25 mM Hepes and $150 \mathrm{mM} \mathrm{KCl}$ ) plus 2 equiv of $\mathrm{Co}(\mathrm{II})$ [CoCo(MetAP)] is shown in Figure 4a. The EPR spectra of MetAP after the addition of 1 and 2 equiv of $\mathrm{Co}$ (II) were indistinguishable in form and integrated to $50 \%$ and $100 \% \pm 5 \%$ of the added cobalt, respectively. The spectra are broad (line widths $>500 \mathrm{G}$ ) and exhibit no resolvable ${ }^{59} \mathrm{Co}$ hyperfine splitting, presumably due to the extensive $g$-strain sometimes associated with high-spin $S=3 / 2 \mathrm{Co}$ (II) centers. The EPR spectrum of [CoCo(MetAP)] was simulated (Figure 4b) by the published protocol for the simulation of high-spin $S=3 / 2$ Co(II) EPR spectra $(\underline{22,23})$. This protocol allows the simulation of line shape by use of theoretically allowed $g_{\text {eff }}$ values corresponding to an isotropic $g_{\text {real }}$ value. The relative magnitudes of $D$ and $E$ reflect the degree of perturbation of the electronic field about the metal ion, providing information about the inner-sphere metal-ligand field strength. Simulation of the [CoCo(MetAP)] EPR spectrum provided $g_{\text {eff }}$ values of 4.85 (4.85), 3.70 (3.69), and 2.10 (2.10) (the $g_{\text {eff }}$ values given are those that gave the best simulation, whereas those in parentheses are the closest allowed by theory). These values correspond to an $M_{s}=\mid \pm 1 / 2>$ ground-state transition with $g_{\text {real }}=2.15$ and $E / D=0.09$.

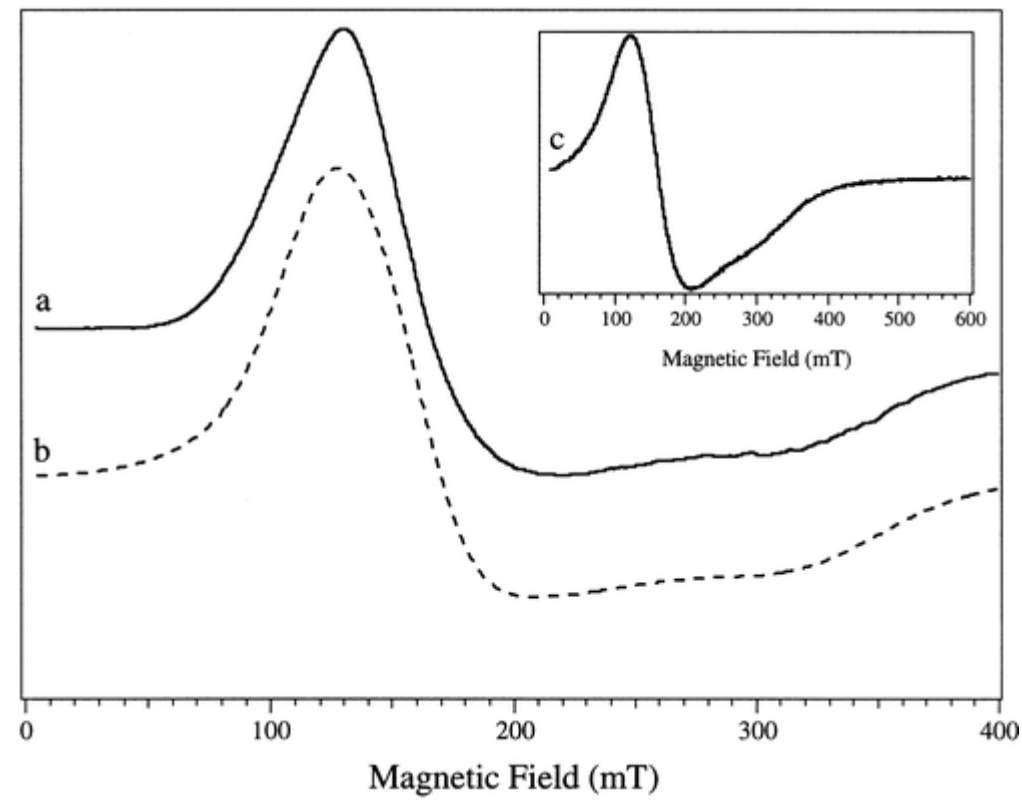

Figure 4 (a) EPR spectrum of [CoCo(MetAP)] in $25 \mathrm{mM}$ Hepes buffer and $150 \mathrm{mM} \mathrm{KCl}, \mathrm{pH} 7.5$, recorded at $9 \mathrm{~K}$, $0.2 \mathrm{~mW}$ microwave power, $1.2 \mathrm{mT}$ field modulation amplitude, $100 \mathrm{kHz}$ modulation frequency, and $10.2 \mathrm{mT} \mathrm{s}^{-1}$ sweep rate. (b) Simulation of spectrum a assuming $g_{\text {eff }}$ values of $4.85,3.70$, and 2.10. These $g_{\text {eff }}$ values correspond to the $M_{\mathrm{s}}=\mid \pm \frac{1}{2}>$ doublet of an $S=3 / 2$ spin system with an isotropic $g_{\text {real }}$ value of 2.15 and an $E / D$ value of 0.09. Inset: (c) EPR spectrum of $\mathrm{CoCl}_{2}$ in $25 \mathrm{mM}$ Hepes buffer, $\mathrm{pH} 7.5$, and $150 \mathrm{mM} \mathrm{KCl}$.

The temperature dependence of the EPR signal observed for [CoCo(MetAP)] was determined (Figure 5). The EPR signal was detectable up to $60 \mathrm{~K}$ and the signal intensity was found to be inversely proportional to the absolute temperature, following Curie law dependence at nonsaturating microwave powers. These data are consistent with the assignment of the EPR transition to a ground-state $M_{s}=\mid \pm 1 / 2>$ doublet. The intensity of the EPR signal from [CoCo(MetAP)] (Figure 5, inset) at $4 \mathrm{~K}$ exhibited typical dependence of the signal intensity on the square root of the microwave power up to much higher power than for the Co(II)-substituted aminopeptidase from Aeromonas proteolytica ([CoCo(AAP)]). These data strongly suggest that, in contrast to [CoCo(AAP)], the $\mathrm{Co}(\mathrm{II})$ 
ions in [CoCo(MetAP)] exhibit no significant spin-spin interaction. In support of these data, no integer spin signal could be detected in the parallel mode for Co(II)-loaded MetAP at pH 7.5.

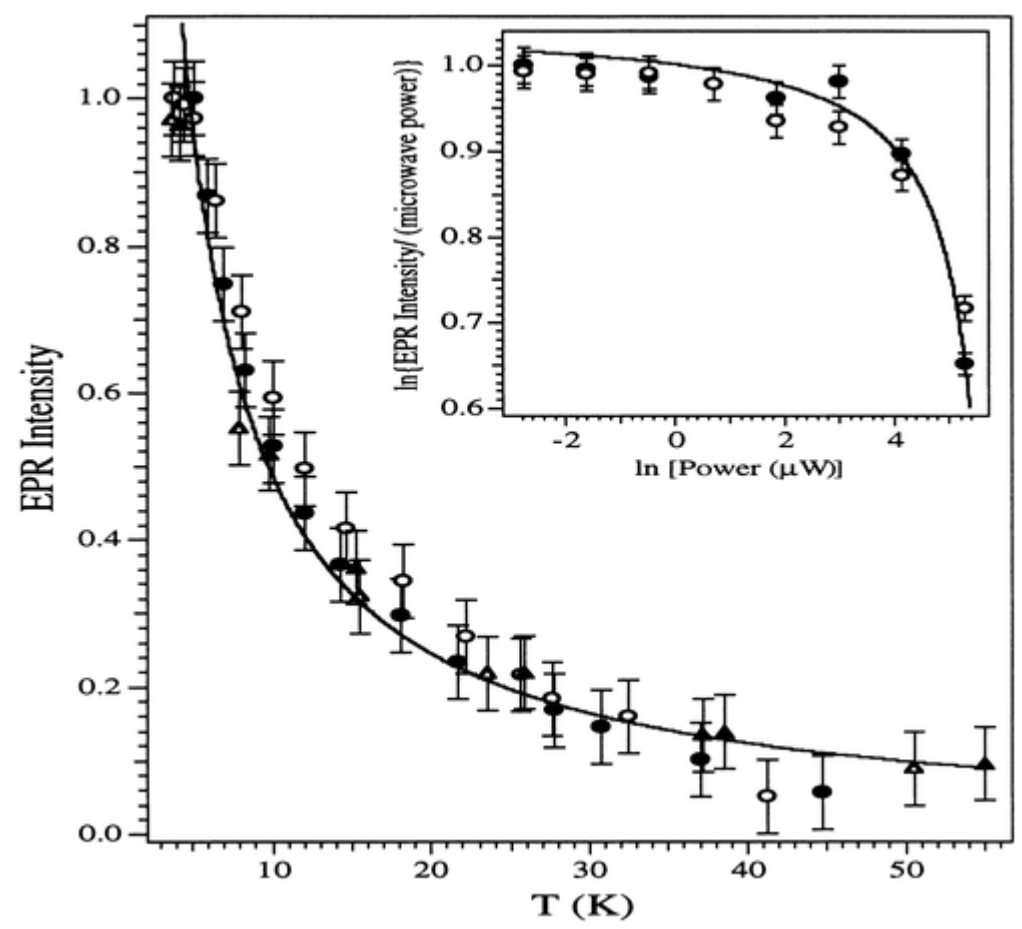

Figure 5 EPR temperature and microwave power dependencies of the observed EPR signals of MetAP. The symbols correspond to MetAP to which 1 (O) and $2(\cdot)$ equivalents of Co(II) were added in $25 \mathrm{mM}$ Hepes buffer, $\mathrm{pH} 7.5$, and $150 \mathrm{mM} \mathrm{KCl}$ and [CoCo(MetAP)] in $15 \mathrm{mM} \mathrm{MOPS}$ and $150 \mathrm{mM} \mathrm{KCl}, \mathrm{pH} 6.0(\Delta)$ and in $50 \mathrm{mM}$ CHES and $150 \mathrm{mM} \mathrm{KCl}, \mathrm{pH} 9.65(\Delta)$. The solid line is a fit to Curie law $1 / T$ dependence. Spectra were recorded at 0.2 $\mathrm{mW}$ microwave power, $1.2 \mathrm{mT}$ field modulation amplitude, $100 \mathrm{kHz}$ modulation frequency, and $10.2 \mathrm{mT} \mathrm{s}^{-1}$ sweep rate. Inset: Microwave power dependency of MetAP to which 1 (0) and 2 (·) equiv of Co(II) were added in $25 \mathrm{mM}$ Hepes buffer, $\mathrm{pH} 7.5$, and $150 \mathrm{mM} \mathrm{KCl}$. All spectra were recorded at $4 \mathrm{~K}$.

EPR spectra were also recorded at pH 6.0 (in $15 \mathrm{mM}$ MOPS and $150 \mathrm{mM} \mathrm{KCl}$; not shown) and at pH 9.65 (in 50 $\mathrm{mM} \mathrm{CHES}$ and $150 \mathrm{mM} \mathrm{KCl}$; Figure 6a). Both spectra were very similar to that observed at $\mathrm{pH} 7.5$ and exhibited temperature dependencies indistinguishable from that of the $\mathrm{pH} 7.5$ spectrum. Double integration of the EPR signal observed for [CoCo(MetAP)] at pH 9.65 accounted for $90 \% \pm 5 \%$ of Co(II) ions in the sample. However, the $S=3 / 2$ signal of [CoCo(MetAP)] at pH 9.65 (Figure 6a) also exhibited a weak signal in the parallel mode with $g_{\text {eff }} \sim$ 12 (Figure 6b). This signal suggests that the two Co(II) ions in the MetAP from E. coli are ferromagnetically coupled, possibly providing an $S=3$ ground state. The temperature dependence of this signal also exhibited Curie law behavior and can therefore be assigned as a ground-state transition. Although integer spin signals cannot be quantified by simple double integration, the observation that the perpendicular mode signal accounts for $\sim 90 \%$ of the added $\mathrm{Co}(\mathrm{II})$ and that both the parallel and perpendicular mode signals appear to be groundstate transitions suggests that only a small population, $\sim 5-15 \%$, of the enzyme molecules contain a spincoupled dinuclear site. The appearance of this $g \sim 12$ signal may be the consequence of deprotonation of a terminal or bridging water molecule. 


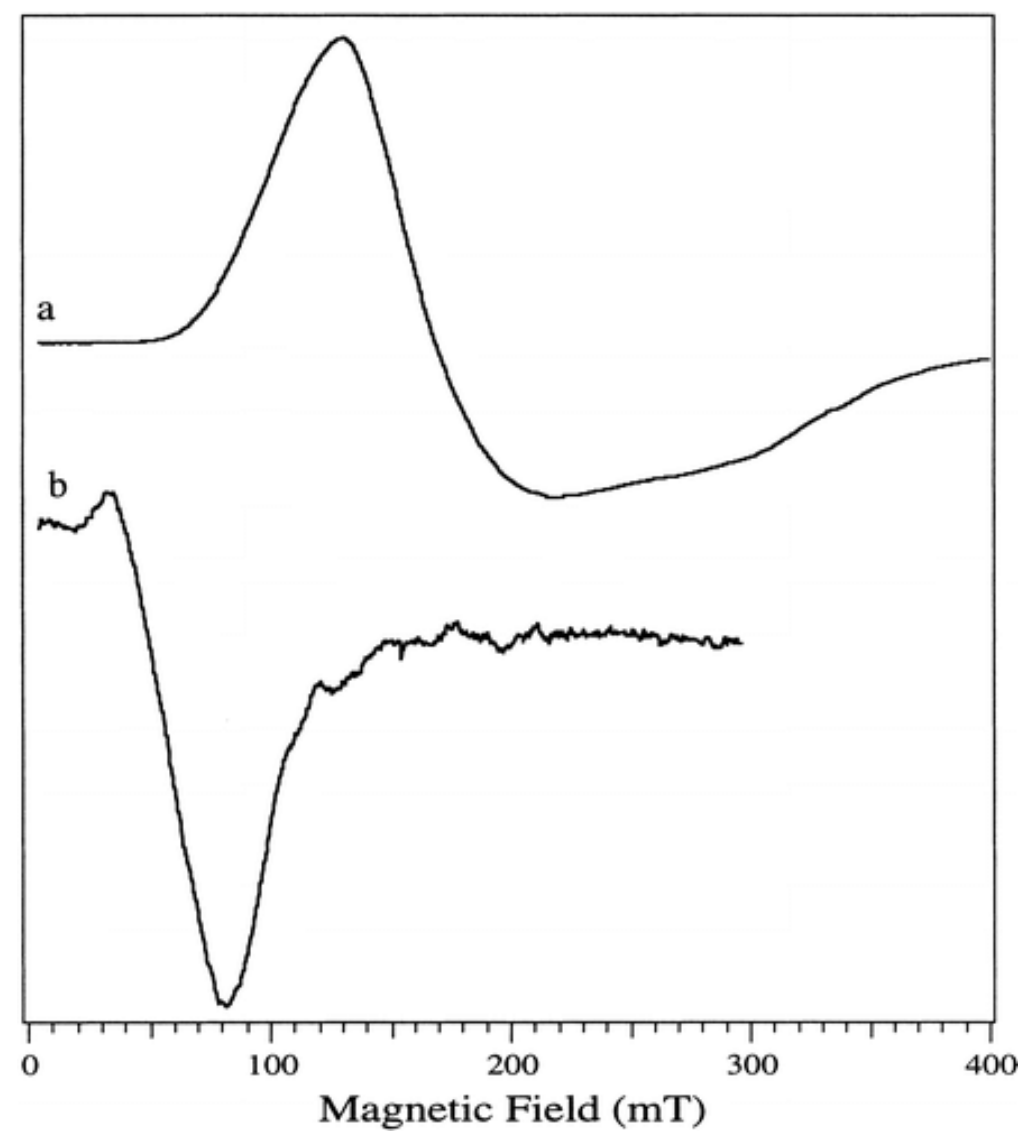

Figure 6 EPR spectra of MetAP at pH 9.65. (a) EPR spectrum of [CoCo(MetAP)] in $50 \mathrm{mM} \mathrm{CHES,} \mathrm{pH} \mathrm{9.65,} \mathrm{and} 150$ $\mathrm{mM} \mathrm{KCl}$. (b) Parallel mode EPR signal from [CoCo(MetAP)] in $50 \mathrm{mM} \mathrm{CHES,} \mathrm{pH} \mathrm{9.65,} \mathrm{and} 150 \mathrm{mM} \mathrm{KCl}$. The intensities have been normalized: the $S=3 / 2$ signal (a) corresponds to $90 \% \pm 5 \%$ of the added $\mathrm{Co}$ (II). The perpendicular EPR spectrum was recorded at $9 \mathrm{~K}$ and $0.2 \mathrm{~mW}$ microwave power, while the parallel mode spectrum was recorded at $9 \mathrm{~K}$ and $5.0 \mathrm{~mW}$. Both spectra were recorded with $1.2 \mathrm{mT}$ field modulation amplitude, $100 \mathrm{kHz}$ modulation frequency and a $10.2 \mathrm{mT} \mathrm{s}^{-1}$ sweep rate.

EPR spectra of the Fe(II)-loaded MetAP from E. coli $(1 \mathrm{mM})$ were also recorded after 1 and 2 equiv of Fe(II) had been added; however, no signals could be observed in either sample in the perpendicular or parallel modes. Thus, the zero-field splitting of the high-spin $S=2 \mathrm{Fe}(\mathrm{II})$ ions is likely $>0.3 \mathrm{~cm}^{-1}$. Fe(II)-loaded forms of the MetAP from $E$. coli were readily oxidized in air, and thus, samples containing 1 and 2 equiv of Fe(III) could be generated. The EPR signals of MetAP containing 1 (not shown) and 2 equiv of Fe(III) were identical in form and integrated to $50 \%$ and $100 \% \pm 5 \%$ of the added iron, respectively (Figure $7 \mathrm{a}$ ). These signals exhibited an essentially isotropic feature at $g_{\text {eff }} \sim 4.3$, typical of mononuclear Fe(III). In addition, a distinct feature at $g_{\text {eff }} \sim 8.9$, a shoulder at $g_{\text {eff }} \sim$ 5.1 , and a broad high-field absorbance around the $g_{\text {eff }} \sim 2$ region were also observed. These signals are characteristic of $\mathrm{Fe}(\mathrm{III})$ bound in an environment with lower than strictly octahedral symmetry. Experimental controls were performed to confirm that the observed signals were not due to uncomplexed or adventitiously associated $\mathrm{Fe}(\mathrm{III})$. Addition of $\mathrm{FeCl}_{3}$ to buffer yielded a precipitate that could be separated by centrifugation, whereas centrifugation of the MetAP sample gave neither a precipitate nor a change in the EPR spectrum. Moreover, adventitiously bound Fe(III) provides an EPR signal clearly lacking in the feature at $g \sim 8.9$ (compare Figure $7 a^{\prime}$ and $\left.b^{\prime}\right)$. An additional control was also performed in which $\mathrm{FeCl}_{3}$ was added to an EDTA solution (Figure $7 \mathrm{c}$ ), producing a spectrum that was also lacking in the feature at $g_{\mathrm{eff}} \sim 8.9$. Thus, the EPR spectrum observed for [Fe(III)Fe(III)(MetAP)] can be assigned to MetAP-bound Fe(III). The microwave power dependence on the intensities of the $g_{\text {eff }} \sim 4.3$ and the $g_{\text {eff }} \sim 8.9$ features at $4 \mathrm{~K}$ were found to be essentially indistinguishable. Moreover, the temperature dependence of the EPR intensity of [Fe(III)Fe(III)(MetAP)] followed Curie law down to $\sim 10 \mathrm{~K}$ (data not shown), and thus, both the $g_{\text {eff }} \sim 4.3$ and the $g_{\text {eff }} \sim 8.9$ features can be 
assigned to ground-state transitions. These data are consistent with the absence of a significant spin-spin interaction between the Fe(III) ions in MetAP.

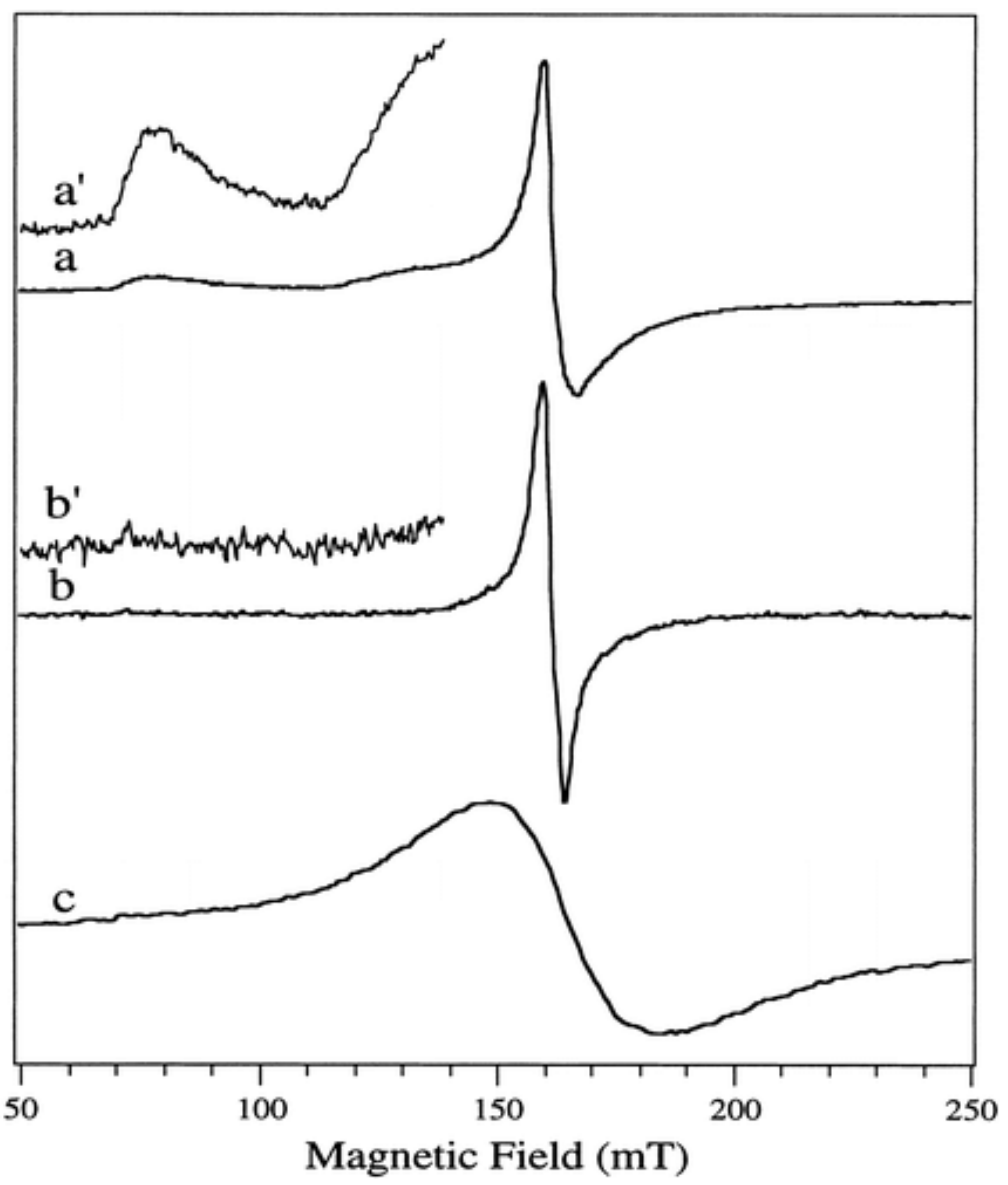

Figure 7 (a) EPR spectrum of MetAP in $25 \mathrm{mM}$ Hepes buffer, $\mathrm{pH} 7.5$, and $150 \mathrm{mM} \mathrm{KCl}$, containing 2 equiv of $\mathrm{Fe}(\mathrm{III})$. (b) EPR spectrum of adventitiously bound Fe(III) to the MutY DNA-binding protein from E. coli. (c) $\mathrm{FeCl}_{3}$-EDTA (0.14 mM) in $25 \mathrm{mM}$ Hepes buffer, $\mathrm{pH} 7.5$, and $150 \mathrm{mM} \mathrm{KCl}$. All spectra were recorded at $4 \mathrm{~K}, 1 \mathrm{~mW}$ microwave power, $1.26 \mathrm{mT}$ field modulation amplitude, $100 \mathrm{kHz}$ modulation frequency, and a $10.2 \mathrm{mT} \mathrm{s}^{-1}$ sweep rate.

NMR Studies. Because only protons proximate to the paramagnetic Co(II) cluster of MetAP are affected, ${ }^{1} \mathrm{H}$ NMR experiments provide a very sensitive fingerprint of the structural and magnetic properties of paramagnetic metalloprotein active sites (25-27). The ${ }^{1} \mathrm{H}$ NMR spectra of a $2 \mathrm{mM}$ Co(II)-substituted MetAP sample in $25 \mathrm{mM}$ borate buffer, $\mathrm{pH} 7.5$, and $500 \mathrm{mM} \mathrm{KCl}$ to which only 1 equiv of $\mathrm{Co}(\mathrm{II})$ was added were recorded in both $\mathrm{H}_{2} \mathrm{O}$ and $\mathrm{D}_{2} \mathrm{O}$ solutions (Figure 8). Several sharp, well-resolved hyperfine-shifted ${ }^{1} \mathrm{H}$ NMR signals were observed in the 100 to $-50 \mathrm{ppm}$ chemical shift range. All of these signals sharpen and shift toward the diamagnetic region as the temperature is increased, indicating Curie-type behavior. Hyperfine-shifted protons in this chemical shift range have previously been observed for proteins containing $\mathrm{Co}(\mathrm{II})$ centers and can be assigned to $\mathrm{N}-\mathrm{H}$ and $\mathrm{C}-\mathrm{H}$ protons of cluster histidine, aspartate, and glutamate residues (28-32). Comparison of the Co(II)MetAP spectra recorded in $\mathrm{H}_{2} \mathrm{O}$ - and $\mathrm{D}_{2} \mathrm{O}$-buffered solution indicates that a single hyperfine-shifted signal, at $92 \mathrm{ppm}$, was solvent-exchangeable (Figure 8). Since only one histidine residue (His171) resides at the dinuclear metal binding site of MetAP $(\underline{14}, 15)$, this signal is assigned to the $\mathrm{N}^{\varepsilon}-\mathrm{H}$ proton of His171. 


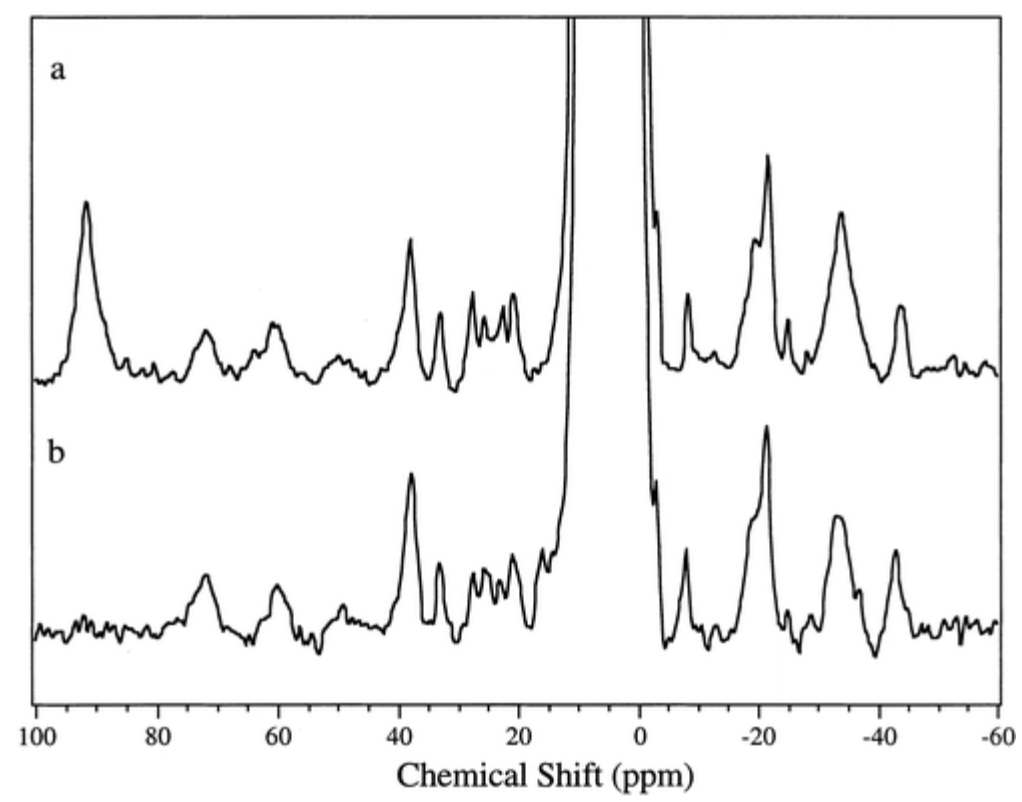

Figure $8{ }^{1} \mathrm{H}$ NMR spectra of MetAP after the addition of 1 equiv of $\mathrm{Co}(\mathrm{II})$ at $25^{\circ} \mathrm{C}$ in $25 \mathrm{mM}$ borate buffer, $\mathrm{pH} 7.6$, and $500 \mathrm{mM} \mathrm{KCl}$ in (a) $\mathrm{H}_{2} \mathrm{O}$ and (b) $\mathrm{D}_{2} \mathrm{O}$ buffer.

\section{Discussion}

Several aminopeptidases, including all of the MetAPs studied to date, have been proposed to be members of a growing class of metallohydrolases that contain two metal ions in the enzyme active site $(\underline{33-38})$. It has been suggested that these enzymes use different metal ion Lewis acidities in discrete dinuclear sites to (i) bind and position substrate, (ii) bind and activate a water molecule to yield an active site hydroxide nucleophile, and/or (iii) stabilize the transition state of the hydrolytic reaction. Despite their ubiquity and the considerable structural information available, the role of each divalent metal ion in these bridged, dimetallic centers during catalytic turnover is still unclear. For MetAPs, all enzymes studied to date have been reported to be Co(II)-dependent metalloproteases. The conclusion that MetAPs are cobalt-dependent enzymes was arrived at from the reproducible observations that MetAPs show maximal catalytic activity with Co(II) when compared to the activity levels of other divalent metal ions. However, the identity of the metal ion in vivo has not been established but, on the basis of whole-cell metal analyses, iron, manganese, and zinc were suggested as potential in vivo candidates (19). In a recent study on the MetAP from E. coli, the combination of whole-cell metal ion concentrations and activity measurements with in vitro activity measurements and substrate binding constants suggested that the MetAP from E. coli can function as an Fe(II) enzyme (19). To gain insight into the divalent metal binding properties of the MetAP from $E$. coli, we have investigated the enzymatic activity as a function of $\mathrm{Co}(\mathrm{II}), \mathrm{Fe}(\mathrm{II})$, and $\mathrm{Zn}(\mathrm{II})$.

Activity measurements as a function of added Co(II) and Fe(II) clearly, and perhaps surprisingly, show that the enzyme is maximally stimulated upon the addition of only one metal ion. The addition of up to 4 equiv of $\mathrm{Co}$ (II) or Fe(II) did not change the observed catalytic activity. Moreover, ICP-AES analyses indicate that upon the addition of divalent metal ions, only one tightly bound divalent metal ion is found per enzyme molecule. Therefore, the second metal ion is loosely associated with the MetAP enzyme. The loose association of Co(II) to MetAPs has previously been shown for the MetAPs from S. cerevisiae (39) and the human homologue of rat initiation factor 2 -associated protein $\left(\mathrm{p}^{67}\right)(\underline{40})$. Fits of the activity data provided the metal ion dissociation constants $\left(K_{\mathrm{d}}\right)$ at $\mathrm{pH} 7.5$ for the $\mathrm{Co}(\mathrm{II})-\left(K_{\mathrm{d}}=0.3 \mu \mathrm{M}\right)$ and Fe(II)-loaded $\left(K_{\mathrm{d}}=0.2 \mu \mathrm{M}\right)$ MetAP from E. coli. Since only one metal ion is bound to the enzyme active site, these $K_{\mathrm{d}}$ values correspond to the microscopic binding constants for the binding of a single metal ion to the active site of MetAP. These values are similar to $K_{d}$ values 
obtained for several hydrolytic enzymes that contain dinuclear, carboxylate-rich active sites. For example, the $K_{\mathrm{d}}$ values for the first metal binding site of the aminopeptidase from $A$. proteolytica $\left(K_{d} \sim 0.001 \mu \mathrm{M}\right)(\underline{41})$, the clostridial aminopeptidase $\left(K_{d}=2 \mu \mathrm{M}\right)(\underline{42})$, the clostridial AMPP $\left(K_{d}=7 \mu \mathrm{M}\right)(\underline{42})$, and the $\beta$-lactamase from Bacillus cereus $\left(K_{d}=0.7 \mu \mathrm{M}\right)(\underline{43})$ are all similar in magnitude to those determined for the MetAP from E. coli.

Interestingly, the addition of $\mathrm{Zn}(\mathrm{II})$ to the MetAP from $E$. coli under aerobic conditions did not stimulate detectable catalytic activity under our assay conditions. In fact, no activity above the detection limit was observed for Zn(II)- loaded MetAP even up to 200 equiv of added metal ion. The MetAP from E. coli is similar to the type I MetAP from S. typhimurium in that this enzyme also showed no activity in the presence of $\mathrm{Zn}(\mathrm{II})$ (ㄴ4). Zinc(II) ions were also found to be inhibitory for the MetAPs from porcine liver ( $\underline{45})$ and the human homologue of the rat initiation factor 2-associated protein $\left(\mathrm{p}^{67}\right)(\underline{40})$. However, a recent study on the type I MetAP from $S$. cerevisiae suggested that $\mathrm{Zn}(\mathrm{II})$ ions, in the presence of $5 \mathrm{mM}$ glutathione and $2 \mathrm{mM}$ EDTA under aerobic conditions, provided an active MetAP enzyme while the Co(II)-containing enzyme was largely inactivated under similar conditions (18). The addition of glutathione to the $\mathrm{Zn}(\mathrm{II})$-loaded MetAP from E. coli under anaerobic conditions was also shown to stimulate catalytic activity, but the overall activity was still only $9 \%$ of the $\mathrm{Co}$ (II)- or Fe(II)-loaded enzymes under similar conditions (19). The role of glutathione, a cellular reductant, is not clear; however, nearly all type I MetAPs contain at least one conserved active-site Cys residue (Cys70 in the MetAP from $E$. coli) ( $\underline{13})$. Since $\mathrm{Zn}(\mathrm{II})$ has a high affinity for thiolate ligands $(\underline{46})$ and, the MetAP from $E$. coli contains three tightly bound $\mathrm{Zn}(\mathrm{II})$ ions in enzyme samples prepared under aerobic conditions in the absence of glutathione but one or two coordinated $\mathrm{Zn}(\mathrm{II})$ ions after treatment with glutathione under anaerobic conditions, we propose that in the absence of glutathione an additional $\mathrm{Zn}(\mathrm{II})$ ion is coordinated to the active-site Cys residues, Cys 59 and Cys70, thus inhibiting the catalytic activity.

It is not unprecedented for metallohydrolases that have crystallographically characterized dinuclear active sites to exhibit catalytic activity with only one metal ion bound. For instance, the crystallographically characterized aminopeptidases from $A$. proteolytica and porcine kidney have long been known to be catalytically active with only one divalent metal ion present (41, 47-49). For the MetAP from E. coli, the addition of up to 200 equiv of either $\mathrm{Co}(\mathrm{II})$ or Fe(II) resulted in a decrease in the catalytic activity, similar to the metal binding properties of the type I MetAP from S. cerevisiae but different from those of the aminopeptidases from A. proteolytica and porcine kidney $(18,41,47-49)$. These data suggest that the binding of a second metal ion may actually be inhibitory, which would imply that the second metal ion has either no catalytic role or is regulatory. Inhibition of catalytic activity by excess divalent metal ions has also been observed for other mononuclear metalloenzymes such as carboxypeptidase Taq when overexpressed in E. coli ( $\underline{50})$, bovine carboxypeptidase A $(\underline{51,52})$, and thermolysin ( $\underline{53}$ ). Inhibition of carboxypeptidase A was attributed to excess metal ion binding to an amino acid residue in the vicinity of the metallo-active site that was involved in catalysis (프). In addition, the authors proposed that a bridging hydroxide is inserted between the two metal ions, forming a dinuclear site. This proposal was corroborated by $X$-ray crystallography where the structure of carboxypeptidase $A$, as well as that of thermolysin in the presence of excess metal ion, revealed two coordinated metal ions forming a ( $\mu$ hydroxo)dizinc(II) core with a Zn-Zn distance of 3.48 and $3.2 \AA$, respectively (53-55). Therefore, the observation that the addition of excess metal ions to the MetAP from $E$. coli inhibited enzymatic activity suggests that the inhibition is likely due to the occupation of the second metal binding site, similar to carboxypeptidase $A$.

Electronic absorption spectroscopic studies on the Co(II)-loaded MetAP from E. coli revealed absorbance increases upon the addition of more than 1 equiv of $\mathrm{Co}(\mathrm{II})$. These data suggest that a second divalent binding site is occupied at high metal concentrations (i.e., $>2 \mathrm{mM}$ ). Ligand-field theory predicts that optical transitions of tetracoordinate $\mathrm{Co}(\mathrm{II})$ species exhibit intense absorption $\left(\varepsilon>300 \mathrm{M}^{-1} \mathrm{~cm}^{-1}\right)$ in the region of $625 \pm 50 \mathrm{~nm}$ owing to a relatively small ligand-field stabilization energy (21). Conversely, Co(II) complexes with octahedral symmetry have only weak absorption $\left(\varepsilon \leq 30 \mathrm{M}^{-1} \mathrm{~cm}^{-1}\right)$ at higher energies, around $525 \pm 50 \mathrm{~nm}$. On the other hand, pentacoordinate $\mathrm{Co}(\mathrm{II})$ exhibits electronic absorption characteristics intermediate between those of tetrahedral and octahedral $\mathrm{Co}$ (II) centers, displaying moderate absorption intensities $\left(50<\varepsilon<250 \mathrm{M}^{-1} \mathrm{~cm}^{-1}\right)$ and often with 
several maxima between 525 and $625 \mathrm{~nm}$. The visible absorption spectrum of the MetAP from E. coli upon the addition of 1 equiv of $\mathrm{Co}(\mathrm{II})$ ([Co(II)_(MetAP)]) under anaerobic conditions exhibits three resolvable $d-d$ transitions at 580,630 , and $690 \mathrm{~nm}\left(\varepsilon=60,50\right.$, and $20 \mathrm{M}^{-1} \mathrm{~cm}^{-1}$, respectively). These data are consistent with the first $\mathrm{Co}(\mathrm{II})$ ion residing in a pentacoordinate environment, in agreement with recent X-ray crystallographic studies (14). The second Co(II) ion has a complex spectrum comprising at least four bands between 500 and 650 $\mathrm{nm}$ with extinction coefficients that range from 60 to $40 \mathrm{M}^{-1} \mathrm{~cm}^{-1}$. The broad range of observed absorption energies also favors the assignment of the second $\mathrm{Co}(\mathrm{II})$ ion to a pentacoordinate environment.

Fits of the three absorption maxima between 580 and $650 \mathrm{~nm}$ provided the metal ion disassociation constant $\left(K_{\mathrm{d}}\right)$ at $\mathrm{pH} 7.5$ for the second metal binding event to the MetAP from $E$. coli $\left(K_{\mathrm{d}} \sim 2.5 \mathrm{mM}\right)$. Since the binding constant for the first metal binding site was found to be $0.3 \mu \mathrm{M}$, the $K_{\mathrm{d}}$ value obtained from fits of the electronic absorption spectral data is the dissociation constant for the second metal binding site. In addition, a shoulder at $525 \mathrm{~nm}$ is observed after the addition of 2 equiv of Co(II). This band may also be associated with the second metal binding event or possibly a third divalent metal binding site. Subtraction of the mono-Co(II) MetAP absorption spectrum allowed the absorption data to be fit to eq 1, providing a $K_{\mathrm{d}}$ value of $3.0 \mathrm{mM}$. These $K_{\mathrm{d}}$ values are similar to $K_{\mathrm{d}}$ values obtained for the binding of a second metal ion to other hydrolytic metalloenzymes. For example, the $K_{\mathrm{d}}$ values for a second metal ion to coordinate to the bovine carboxypeptidase $A$ and the $\beta$-lactamase from Bacillus cereus are $24 \mu \mathrm{M}$ and $2.7 \mathrm{mM}$, respectively $(\underline{43,52})$. Combination of the $K_{\mathrm{d}}$ value obtained for the first metal binding site, $0.3 \mu \mathrm{M}$, with the $K_{\mathrm{d}}$ value obtained for the second metal binding site, $2.4 \mathrm{mM}$, suggests that under physiological conditions the second metal binding site is likely unoccupied. On the basis of these data, we propose that the MetAP from E. coli can function as a mononuclear hydrolase in vivo.

The observed electronic absorption spectra of Co(II)-loaded MetAP suggests that the Co(II) ions reside in a fairly symmetrical pentacoordinate geometry. These data are consistent with the observed EPR spectra of the $\mathrm{Co}(\mathrm{II})$ loaded MetAP from E. coli, which are broad and featureless. A broad, featureless EPR signal for Co(II) centers suggests an unconstrained ligand field; thus, there is a great deal of flexibility in the ligand environment. A consequence of this is that the $g$-strain, which is a measure of the spread of microheterogeneous ligand geometries, is large. In such a case, EPR line widths would be expected to be broad and ${ }^{57}$ Co hyperfine lines would not easily be observed ( $\underline{56})$. Thus, it is likely that the ligand-sphere geometries of the Co(II) ions are not highly constrained $(\underline{22}, 23)$. Moreover, the low $E / D$ value of 0.09 (in general, $1 / 3 \geq E / D \geq 0$ ) indicates a fairly high degree of axial symmetry. The combination of the electronic absorption and EPR data suggests that both $\mathrm{Co}(\mathrm{II})$ ions in the MetAP from E. coli reside in a trigonal bipyramidal geometry.

The observed EPR signal for [CoCo(MetAP)] was similar to that observed for the dicobalt(II)-substituted aminopeptidase from $A$. proteolytica $\left([\mathrm{CoCo}(\right.$ AAP) $])$ as well as several other $\mathrm{Co}(\mathrm{II})$ systems such as $\left[\mathrm{Co}\left(\mathrm{H}_{2} \mathrm{O}\right)_{6}\right]^{2+}$ (Figure 4c) $(\underline{22,23})$. Signals of this type are typical of $\mathrm{Co}(\mathrm{II})$ species with essentially axial symmetry, and for such systems, EPR spectra of $\mathrm{Co}(\mathrm{II})$ are a relatively insensitive geometric probe. Nevertheless, EPR is useful in distinguishing enzyme-bound $\mathrm{Co}(\mathrm{II})$ from $\left[\mathrm{Co}\left(\mathrm{H}_{2} \mathrm{O}\right)_{6}\right]^{2+}$. Computer simulation of the EPR spectrum of $\mathrm{Co}(\mathrm{II})$ in Hepes buffer, pH 7.9 (not shown), invoked $g_{\text {eff }(x, y, z)}$ values of 5.06 (5.08), 4.04 (4.04), and 2.02 (2.02), which are significantly different from those of [CoCo(MetAP)]. Furthermore, the EPR absorption of $\left[\mathrm{Co}\left(\mathrm{H}_{2} \mathrm{O}\right)_{6}\right]^{2+}$ extends out of zero field, whereas there is no EPR absorption by MetAP in the 0-50 mT region. Therefore, the EPR signal observed upon the addition of 2 equiv of $\mathrm{Co}(\mathrm{II})$ to a $3.9 \mathrm{mM}$ solution of MetAP contained no significant contribution due to unbound $\mathrm{Co}(\mathrm{II})$. This is consistent with our estimate of the second metal binding site being on the order of $2.5 \mathrm{mM}$.

EPR spectroscopy is also useful for obtaining information on the electronic communication between two paramagnetic metal ions in a dinuclear center. The EPR signal observed for [CoCo(MetAP)] follows Curie law over the temperature range 4-60 $\mathrm{K}$ at nonsaturating microwave powers. These data strongly suggest that the $\mathrm{Co}(I I)$ ions in [CoCo(MetAP)] exhibit no significant spin-spin interaction. In support of these data, no integer spin 
signal could be detected in the parallel mode for MetAP at pH 7.5. Similarly, insertion of a second Fe(III) ion into the MetAP active site does not create an enhanced relaxation pathway. Therefore, the two Fe(III) ions in Fe(III)loaded MetAP do not exhibit any significant spin-spin interaction, similar to the two Co(II) ions in Co(II)substituted MetAP. The range of temperatures over which the EPR signals from Co(II)-loaded MetAP were detectable can be compared with the temperature range of the detectable EPR signal from [CoCo(AAP)] $(\underline{22}, 23)$. The two cobalt ions in [CoCo(AAP)] were shown to be spin-coupled, providing a spin-spin relaxation pathway that results in the spectrum of [CoCo(AAP)] obeying $1 / T$ dependence over only a very narrow temperature range (9-15 K). This electronic communication is likely mechanistically important for [CoCo(AAP)] in that a pathway for the modulation of the Lewis acidity of one metal ion by the other is present. Moreover, spin-spin interactions also reveal structural motifs such as $\mu-\mathrm{OH}(\mathrm{H})$ ligands. One can then speculate that the proposed bridging water molecule observed in the X-ray crystal structure of the MetAP from E. coli is incapable of mediating detectable spin-spin coupling between the metal ions at $\mathrm{pH} 7.5$ by EPR spectroscopy. However, at high pH values (>9.0) some spin-spin interaction is observed, suggesting the deprotonation of the bridging water molecule to a bridging hydroxide. Such a hypothesis would provide a rationale for the decrease in catalytic activity upon the binding of the second metal ion, similar to that proposed for carboxypeptidase $A(\underline{51})$.

To rationalize the large difference between the two metal ion binding constants in the MetAP from E. coli, we employed ${ }^{1} \mathrm{H}$ NMR spectroscopy in conjunction with the available $X$-ray crystal structure. The ${ }^{1} \mathrm{H}$ NMR spectra of [Co(II)_(MetAP)] revealed a single exchangeable resonance at $92 \mathrm{ppm}$. Examination of the X-ray crystal structure $(\underline{14})$ revealed the presence of a single active-site histidine ligand, namely, His171. The hyperfine shift and position of the observed exchangeable signal is consistent with its assignment as the $\mathrm{N}-\mathrm{H}$ proton of an $\mathrm{N}^{\varepsilon 2}$ coordinated histidine ligand ( $\underline{26})$. Therefore, these data suggest that the first metal binding site, which is also the catalytically essential metal ion, contains His171. The coordination sphere of the tightly bound Co(II) ion is likely completed by Glu204, Glu235, and Asp108 (Figure 9). Consistent with this interpretation, the scissile carbonyl oxygen of a substrate analogue inhibitor (14), was shown to bind to the histidine-ligated Co(II) ion. As this first metal binding site provides maximal catalytic activity when occupied, it is likely that the active-site nucleophile, a water or hydroxide moiety, constitutes the fifth Co(II) ligand.
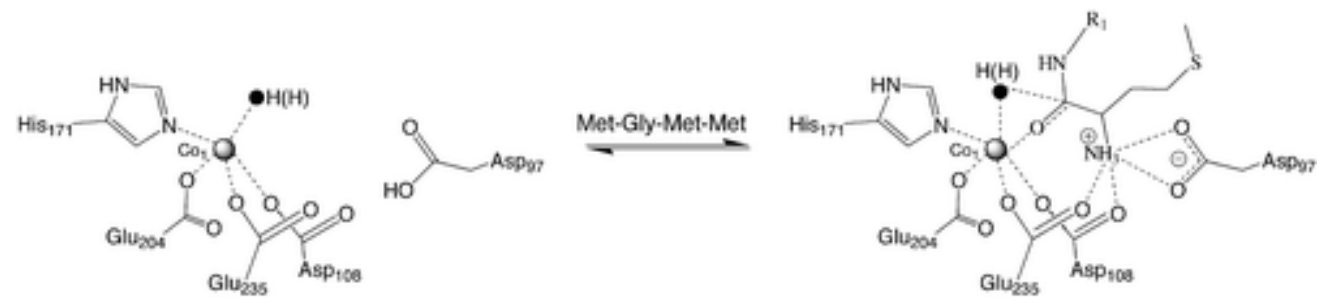

Figure 9 Proposed structure of the mono-Co(II) form of the MetAP from E. coli in the absence and presence of substrate.

It would appear to be contradictory that a crystallographically characterized enzyme with a clear motif for a dinuclear metal-containing active site could function as a mononuclear metalloenzyme. However, the divalent metal binding properties of the MetAP from E. coli appear to be analogous to those of the zinc-dependent $\beta$ lactamase from $B$. cereus. Of the two $\mathrm{Zn}(\mathrm{II})$ ions in the active site of the $\beta$-lactamase from $B$. cereus, the tightly bound $\mathrm{Zn}(\mathrm{II})$ ion is proposed to provide the nucleophile and also act as a Lewis acid to stabilize the tetrahedral transition state $(\underline{57,58})$. The role of the second $\mathrm{Zn}(\mathrm{II})$ ion is unclear since a conserved carboxylate residue is proposed to act as a general base to form the dianion and also to protonate the leaving group, thus facilitating $\mathrm{C}-\mathrm{N}$ bond cleavage. It has, therefore, been suggested that the $B$. cereus enzyme may be an evolutionary intermediate between the mono- and dizinc(II) metallo- $\beta$-lactamases (모). On the basis of this suggestion, it is likely that the active-site nucleophile in the MetAP from E. coli is a water/hydroxide that is coordinated to this first, tightly bound metal ion. EPR studies of Co(II)-substituted MetAP at pH 9.5 provides evidence for spincoupling via a $\mu$-hydroxide moiety, suggesting that at $\mathrm{pH} 7.5$ there would be a $\mu$-aquo bridge from which the active-site nucleophile is derived, as appears to be the case for the aminopeptidase from A. proteolytica $(22,23$, 
60). It is tempting to speculate that the need to break this bridge provides an activation barrier that is responsible for the lower activity of the dicobalt- and diiron-substituted MetAP enzymes compared to the mononuclear enzyme analogues.

Based on previously reported kinetic, molecular modeling, and X-ray crystallographic data, a mechanism of action for the MetAP from E. coli was recently proposed $(\underline{14,61)})$. In this mechanism, the peptide carbonyl oxygen was suggested to coordinate to the histidine-ligated divalent metal atom. The catalytic role attributed to other residues in the active site included hydrogen-bond formation between His 79 and the backbone $\mathrm{N}-\mathrm{H}$ scissile peptide bond, thereby stabilizing the leaving group. In addition, glutamate 204, which is also a ligand to the histidine-containing divalent metal ion, was proposed to be a proton acceptor/donor in the catalytic process. The role of the second divalent metal ion was to bind and position the terminal amino group of the polypeptide chain. Indeed, in the crystal structure of the MetAP from E. coli with a substrate analogue inhibitor bound (14), the cationic $\mathrm{N}$-terminal amine nitrogen of the inhibitor is coordinated to the second $\mathrm{Co}(\mathrm{II})$ ion. However, these data do not distinguish between a mechanism in which the second, noncatalytic metal ion plays an integral role in catalysis and one in which the second metal ion is not necessarily involved in the catalytic reaction. The binding studies, presented herein, suggest that at physiological concentrations of divalent metal ion the lability of the non-histidine-coordinated metal ion would preclude the existence of a dinuclear site in MetAP. Therefore, we propose that the catalytic role ascribed to the non-histidine-coordinated metal ion must be performed instead by the active-site amino acid groups Asp97, Asp108, and Glu235, which form a negative pocket in the appropriate position to bind the $\mathrm{N}$-terminal amine moiety (Figure 9). This proposal is consistent with sitedirected mutagenesis studies on the type I MetAP from S. cerevisiae in which Asp219 was substituted to Asn (Asp219 corresponds to Asp97 in the MetAP from E. coli) (62). In this study, the catalytic activity decreased 5fold but the enzyme retained one tightly bound metal ion. Moreover, a recent study in which Asp97 of the MetAP from E. coli was mutated to Ala revealed that no enzymatic activity could be detected and that the mutant enzyme was in the apo form ( $\underline{63})$. Thus, the negative charge of Asp97 is critical in catalysis and its replacement by an alkyl group, such as Ala, results in the inability of the MetAP enzyme to bind divalent metal ions.

In conclusion, the data presented herein have shown that the MetAP from E. coli contains a high- and a lowaffinity metal binding site and that the enzyme is maximally active when only one metal binding site is occupied. On the basis of the observed catalytic activity and the observed metal binding constants, the MetAP from E. coli likely functions, in vivo, as a mononuclear enzyme. Additionally, the high-affinity metal binding site was clearly assigned as the histidine-containing site and, therefore, is the catalytically relevant metal binding site. The combination of these data with previously reported kinetic, spectroscopic, and X-ray crystallographic results suggests that the coordination of a second divalent metal ion is not required in catalysis. Therefore, its proposed role of binding and positioning the cationic $\mathrm{N}$-terminal amine group is likely performed by the negatively charged active-site residues Asp97, Asp108, and Glu235.

\section{Acknowledgment}

The methionyl aminopeptidase from E. coli was purified from a stock culture kindly provided by Drs. Brian Matthews and W. Todd Lowther.

\section{References}

1 Bradshaw, R. A. (1989) Trends Biochem. Sci.14, 276-279.

2 Meinnel, T., Mechulam, Y., and Blanquet, S. (1993) Biochimie75, 1061-1075.

$\underline{\mathbf{3}}$ Bradshaw, R. A., Brickey, W. W., and Walker, K. W. (1998) Trends Biochem. Sci23, 263-267.

4 Arfin, S. M., and Bradshaw, R. A. (1988) Biochemistry27, 7979-7984.

$\underline{5}$ Chang, S.-Y. P., McGary, E. C., and Chang, S. (1989) J. Bacteriol.171, 4071-4072.

$\underline{6}$ Miller, C. G., Kukral, A. M., Miller, J. L., and Movva, N. R. (1989) J. Bacteriol.171, 5215-5217.

$\underline{7}$ Li, X., and Chang, Y.-H. (1995) Proc. Natl. Acad. Sci. U.S.A.92, 12357-12361. 
8 Taunton, J. (1997) Chem. Biol.4, 493-496.

$\underline{9}$ Griffith, E. C., Su, Z., Turk, B. E., Chen, S., Chang, Y.-H., Wu, Z., Biemann, K., and Liu, J. O. (1997) Chem. Biol.4, 461-471.

Sin, N., Meng, L., Wang, M. Q., Wen, J. J., Bornmann, W. G., and Crews, C. M. (1997) Proc. Natl. Acad. Sci. U.S.A.94, 6099-6103.

11 Lowther, W. T., McMillen, D. A., Orville, A. M., and Matthews, B. W. (1998) Proc. Natl. Acad. Sci. U.S.A.95, 12153-12157.

12 Liu, S., Widom, J., Kemp, C. W., Crews, C. M., and Clardy, J. (1998) Science282, 1324-1327.

13 Tahirov, T. H., Oki, H., Tsukihara, T., Ogasahara, K., Yutani, K., Ogata, K., Izu, Y., Tsunasawa, S., and Kato, I. (1998) J. Mol. Biol.284, 101-124.

14 Lowther, W. T., Orville, A. M., Madden, D. T., Lim, S., Rich, D. H., and Matthews, B. W. (1999) Biochemistry38, 7678-7688.

15 Roderick, S. L., and Matthews, B. W. (1993) Biochemistry32, 3907-3912.

16 Barrett, A. J., Rawlings, N. D., and Woessner, J. F. (1998) pp 1-1666, Academic Press, London.

17 Taylor, A. (1996) in Molecular Biology Intelligence Unit, pp 1-219, R. G. Landes Co., Austin, TX.

18 Walker, K. W., and Bradshaw, R. A. (1998) Protein Sci.7, 2684-2687.

19 D'souza, V. M., and Holz, R. C. (1999) Biochemistry38, 11079-11085.

Holm, R. H., Kennepohl, P., and Solomon, E. I. (1996) Chem. Rev.96, 2239-2314.

$\underline{21}$ Bertini, I., and Luchinat, C. (1984) Adv. Inorg. Biochem.6, 71-111.

22 Bennett, B., and Holz, R. C. (1997) J. Am. Chem. Soc.119, 1923-1933.

23 Bennett, B., and Holz, R. C. (1997) Biochemistry36, 9837-9846.

24Winzor, D. J., and Sawyer, W. H. (1995) Quantitative Characterization of Ligand Binding, Wiley-Liss, New York.

$\underline{25}$ Bertini, I., and Luchinat, C. (1986) NMR of Paramagnetic Molecules in Biological Systems, Benjamin \& Cummings, Menlo Park, CA.

$\underline{26}$ Bertini, I., Turano, P., and Vila, A. J. (1993) Chem. Rev.93, 2833-2932.

$\underline{\mathbf{2 7}}$ La Mar, G. N., and de Ropp, J. S. (1993) in Biological Magnetic Resonance: NMR of Paramagnetic Molecules. (Berliner, L. J., and Reuben, J., Eds.) pp 1-78, Plenum Press, New York.

28 Dennison, C., Berg, A., de Vries, S., and Canters, G. W. (1996) FEBS Lett.394, 340-344.

29 Dennison, C., Berg, A., and Canters, G. W. (1997) Biochemistry36, 3262-3269.

Bertini, I., Bren, K. L., Clemente, A., Fee, J. A., Gray, H. B., Luchinat, C., Malmström, B. G., Richards, J. H., Sanders, D., and Slutter, C. (1996) J. Am. Chem. Soc.118, 11658-11659.

31 Luchinat, C., Sorianio, A., Djinovic-Carugo, K., Saraste, M., Malmström, B. G., and Bertini, I. (1997) J. Am. Chem. Soc.119, 11023-11027.

32 Salgado, J., Warmerdam, G., Bubacco, L., and Canters, G. W. (1998) Biochemistry37, 7378-7389.

33 Vallee, B. L., and Auld, D. S. (1993) Proc. Natl. Acad. Sci. U.S.A.90, 2715-2718.

34 Vallee, B. L., and Auld, D. S. (1993) Biochemistry 32, 6493-6500.

$\underline{35}$ Sträter, N., Lipscomb, W. N., Klabunde, T., and Krebs, B. (1996) Angew. Chem., Int. Ed. Engl.35, 2024-2055.

36 Lipscomb, W. N., and Sträter, N. (1996) Chem. Rev.96, 2375-2433.

37 Wilcox, D. E. (1996) Chem. Rev.96, 2435-2458.

38 Dismukes, G. C. (1996) Chem. Rev.96, 2909-2926.

39 Zuo, S., Guo, Q., Ling, C., and Chang, Y.-H. (1995) Mol. Gen. Genet.246, 247-253.

$\mathrm{Li}, \mathrm{X}$. , and Chang, Y.-H. (1996) Biochem. Biophys. Res. Commun.227, 152-159.

$\underline{41}$ Prescott, J. M., and Wilkes, S. H. (1976) Methods Enzymol.45B, 530-543.

42 Fleminger, G., and Yaron, A. (1984) Biochim. Biophys. Acta789, 245-256.

$\underline{43}$ Baldwin, G. S., Galdes, A., Hill, H. A., Waley, S. G., and Abraham, E. P. (1980) J. Inorg. Biochem.13, 189-204.

44 Miller, C. G., Strauch, K. L., Kukral, A. M., Miller, J. L., Wingfield, P. T., Mazzei, G. J., Werlen, R. C., Graber, P., and Movva, N. R. (1987) Proc. Natl. Acad. Sci. U.S.A.84, 2718-2722.

$\underline{45}$ Kendall, R. L., and Bradshaw, R. A. (1992) J. Biol. Chem.267, 20667-20673.

$\underline{46}$ Cotton, F. A., Wilkinson, G., Murillo, C. A., and Bochmann, M. (1999) Advanced Inorganic Chermistry, 6th ed., John Wiley \& Sons, New York. 
47 Prescott, J. M., Wagner, F. W., Holmquist, B., and Vallee, B. L. (1983) Biochem. Biophys. Res. Commun.114, 646-652.

48 Prescott, J. M., Wagner, F. W., Holmquist, B., and Vallee, B. L. (1985) Biochemistry24, 5350-5356.

49 Lehky, P., Lisowski, J., Wolf, D. P., Wacker, H., and Stein, E. A. (1973) Biochim. Biophys. Acta321, 274-281.

Lee, S. H., Taguchi, H., Yoshimura, E., Minagawa, E., Kaminogawa, S., Ohta, T., and Matsuzawa, H. (1994) Biosci. Biotechnol. Biochem.58, 1490-1495.

$\underline{\mathbf{5 1}}$ Larsen, K. S., and Auld, D. S. (1989) Biochemistry28, 9620-9625.

$\underline{52}$ Larsen, K. S., and Auld, D. S. (1991) Biochemistry30, 2613-2618.

53 Holland, D. R., Hausrath, A. C., Juers, D., and Matthews, B. W. (1995) Protein Sci.4, 1955-1965.

$\mathbf{5 4}$ Gomez-Ortiz, M., Gomis-Ruth, F. X., Huber, R., and Aviles, F. X. (1997) FEBS Lett.400, 336-340.

$\underline{55}$ Bukrinsky, J. T., Bjerrum, M. J., and Kadziola, A. (1998) Biochemistry37, 16555-16564.

$\underline{\mathbf{5 6}}$ Bennett, B., and Holz, R. C. (1998) J. Am. Chem. Soc.120, 12139-12140.

$\underline{57}$ Concha, N. O., Rasmussen, B. A., Bush, K., and Hertzberg, O. (1996) Structure4, 823-836.

58 Bounaga, S., Laws, A. P., Galleni, M., and Page, M. I. (1998) Biochem. J.331, 703-711.

59 Fabiane, S. M., Sohi, M. K., Wan, T., Payne, D. J., Bateson, J. H., Mitchell, T., and Sutton, B. J. (1998) Biochemistry37, 12404-12411.

DePaola, C., Bennett, B., Holz, R. C., Ringe, D., and Petsko, G. (1999) Biochemistry38, 9048-9053.

$\underline{61}$ Lowther, T. W., Zhang, Y., Sampson, P. B., Honek, J. F., and Matthews, B. W. (2000) Biochemistry (in press).

$\underline{62}$ Klinkenberg, M., Ling, C., and Chang, Y. H. (1997) Arch. Biochem. Biophys.347, 193-200.

63 Chiu, C.-H., Lee, C.-Z., Lin, K.-S., Tam, M. F., and Lin, L.-Y. (1999) J. Bacteriol.181, 4686-4689.

$\underline{1}$ Abbreviations: MetAP, methionyl aminopeptidase; EPR, electron paramagnetic resonance; NMR, nuclear magnetic resonance; ICP-AES, inductively coupled plasma-atomic emission spectroscopy; HEPES, $N$-(2hydroxyethyl)piperazine- $N$ '-2-ethanesulfonic acid; CHES, 2-(N-cyclohexylamino)ethylsulfonic acid; MOPS, 3-(Nmorpholino)propanesulfonic acid. 